the patient's interpreter and support. Forty-two per cent received under five days' speech therapy, which reflects the important part played in speech therapy by assessment, as these patients were judged to be unsuitable for treatment because their defect was either minimal or too severe. Once accepted for speech therapy patients tended to receive it for a longer time; $21^{\circ}$ of those treated were still receiving speech therapy more than one year after the stroke, compared with $10^{\circ}$ " of those receiving physiotherapy and $6^{\circ}{ }_{0}$ of those receiving occupational therapy.

The therapists' judgment of good progress as an indicator for stopping treatment was similar for occupational therapy and physiotherapy $\left(37^{\circ}{ }^{\prime}\right.$ and $38^{\circ}{ }^{\circ}$ of cases treated). Far fewer patients, however, stopped physiotherapy than occupational therapy and speech therapy because of lack of progress.

\section{References}

${ }^{1}$ Lowenthal, M, New York State fournal of Medicine, 1960, 60, 3235.

2 Rankin, J, Scottish Medical fournal, 1957, 2, 127.

3 Waylonis, G W, Keith, M W, and Aseff, J N, Archives of Physical Medicine and Rehabilitation, 1973, 54, 151

${ }^{+}$Hoberman, M, and Springer, C F, Archives of Physical Medicine and Rehabilitation, 1958, 39, 235.

5 Lehann, J F, et al, Archives of Physical Medicine and Rehabilitation, 1975, $\mathbf{5 6}, 375$.
${ }^{6}$ Wylie, C M, Geriatrics, 1970, 25, 107.

'Benton, J G, et al, American Heart fournal, 1959, 42, 719.

${ }^{8}$ Feldman, D J, et al, fournal of Chronic Diseases, 1962, 15, 297.

${ }^{9}$ Stern, P H, et al, Stroke, 1971, 2, 213.

10 Adams, G F, British Medical fournal, 1971, 1, 91

11 Bourestom, M C, Archives of Physical Medicine and Rehabilitation, 1967, 足 48, 415 .

12 Rosenthal, H A, Pennsylvania Medical fournal, 1961, 64, 56.

${ }^{13}$ Bruell, H J, and Simon, J I, Archives of Physical Medicine and Rehabilitation, 1960, 41, 564.

${ }^{14}$ Mahoney, F I, and Bartel, S J, Archives of Physical Medicine and Rehabilitation, 1954, 35, 359.

${ }^{15}$ Adams, G F, and McComb, S G, Lancet, 1953, 2, 266.

${ }^{16}$ Wilkes, E, Physiotherapy, 1975, 61, 365.

17 Lowenthal, M, Tobis, J S, and Howard, I R, Archives of Physical Medicine $\frac{\overline{\bar{O}}}{\bar{S}}$ and Rehabilitation, 1959, 40, 183.

${ }^{1 *}$ Brocklehurst, J C, et al, Age and Ageing. In press.

${ }^{19}$ Andrews, K, in Medical, Social, and Psychological Aspects of Stroke: Final Report. Department of Geriatric Medicine, University of Manchester, 1978

2" Andrews, K, et al, in Medical, Social, and Psychological Aspects of Stroke: Final Report. Department of Geriatric Medicine, University of Man- $\overrightarrow{-}$ chester, 1978.

21 Licht, S, Stroke-Its Rehabilitation, ed S Licht. New Haven, Licht, 1975.

22 Bard, S, and Hirschberg, G G, Archives of Physical Medicine and Re- 3 habilitation, 1965, 46, 567 .

${ }^{23}$ Hurd, M M, Farrell, K H, and Waylouis, G W, Archives of Physical $\vec{\sigma}$ Medicine and Rehabilitation, $1974, \mathbf{5 5}, 519$.

24 Granger, C V, et al, Stroke, 1975, 6, 34.

\title{
Subarachnoid haemorrhage: long-term follow-up results of late surgical versus conservative treatment
}

\author{
MARKKU KASTE, HENRY TROUPP
}

British Medical fournal, 1978, 1, 1310-1311

\section{Summary and conclusions}

During 1964-9, 178 patients with subarachnoid haemorrhage from a single intracranial arterial aneurysm were allocated at random to receive operative or conservative treatment at an average of seven weeks after bleeding. During the follow-up fatal rebleeding episodes occurred in six of the 86 patients treated surgically and 16 of the 92 treated conservatively. This difference was significant. Fatal rebleeding occurred on average 40 months after the first episode. Deaths from all causes occurred in 17 of the 86 patients treated surgically and 22 of the 92 treated conservatively. Life-table analysis of the chances of surviving 1, 5, and 11 years gave probabilities of 95 and $91 \%, 87$ and $86 \%$, and 76 and $75 \%$ in the two treatment groups respectively. Of the 139 patients alive after a mean follow-up of nine years, $130(94 \%)$ were fully independent in their daily lives, and only $43(31 \%)$ were unable to work. The method of treatment did not affect the quality of survival.

The results show that fatal rebleeding may occur even many years after the first episode. Nevertheless, if the

University Department of Neurology, SF-00290 Helsinki 29, Finland MARKKU KASTE, MD, senior lecturer in neurology

University Department of Neurosurgery, SF-00260 Helsinki 26, Finland

HENRY TROUPP, MD, professor of neurosurgery patient is in good condition seven weeks after a haemor- $\overrightarrow{\vec{O}}$ rhage from a single intracranial arterial aneurysm the outcome is good irrespective of whether operation is performed at this late stage.

\section{Introduction}

A few randomised clinical trials of surgery for intracranial arterial aneurysm have been reported, ${ }^{1-6}$ but data on long-term 3 follow-up are scarce. ${ }^{--9}$ We therefore report the results of ao follow-up of patients who had been included in a controlled trial of late surgery for aneurysm an average of nine years $\sigma$ previously. ${ }^{+}$The patients had been allocated to receive either $\rightarrow$ surgical or conservative treatment at an average of seven weeks after the haemorrhage. Patients who survive in good condition N this long after a bleeding episode are already set on a recovery $\mathbb{\omega}_{\mathrm{E}}$ course and are also likely to do well at operation. A decision to operate at this late stage is thus not a foregone conclusion. The results provide data on aneurysmal disease and its possible $\frac{\mathbb{\Phi}}{\mathbb{C}}$ association with other vascular disorders.

\section{Patients and methods}

Between 1 April 1964 and 31 March 1969, 178 patients with subarachnoid haemorrhage from a single intracranial arterial aneurysm were allocated at random to receive either operative or conservativeo treatment. The mean delay between the bleeding episode and the decision to treat was seven weeks. Reasons for the delay were a shortage of neurosurgical resources and an unawareness of the importance? of the time factor.

The patients were carefully matched for age, sex, blood pressure, state of consciousness, and site of the aneurysm, according to the principles of McKissock et al. ${ }^{1-3}$ Eighty-six underwent surgery and 
92 were treated conservatively. Questionnaires were sent to the patients once a year during the first five years and again in April 1976. All the patients were traced, death certificates and necropsy records being examined for those who had died.

Statistical comparisons were carried out with Student's $t$ test, the $\%^{2}$ test, and a life-table method.

\section{Results}

The mean duration of follow-up of the patients alive in April 1976 was 109 months. By then, 39 had died (table I). Six of the 86 patients in the surgical group had fatal rebleeding; four of these had had unsatisfactory operations, and one additional patient died in the postoperative period. Sixteen fatal rebleeding episodes occurred among the 92 patients treated conservatively $(\mathrm{P}<0.05)$. Fatal rebleeding occurred on average 40 months after the first episode: the individua times (in months) were $1,3,6,44,50$, and 61 in the surgical group, and $1,1,1,1,2,2,3,4,17,57,81,85,98,104,123$, and 139 in the group treated conservatively. Of the patients who died from rebleeding, 12 were men and 10 women.

The mean age at the time of the initial haemorrhage was 40 years, median 41 . The mean age at death of those with fatal rebleeding was 43 years, median 45 ; and the mean age at death of patients dying from other causes was 53 years, median 55 . The incidence of rebleeding did not differ significantly with the site of the aneurysmnamely, internal carotid, middle cerebral, or anterior communicating artery.

Life-table analysis of the chances of survival in the surgical and conservative-treatment groups gave probabilities of 95 and $91 \%$ surviving one year, 87 and $86 \%$ surviving five years, and 76 and $75 \%$ surviving 11 years respectively (see figure).

Of the 139 patients alive at the end of the follow-up period, 65

TABLE I-Deaths from all causes in the two treatment groups up to April 1976

\begin{tabular}{lc|c|c|c|c|c}
\hline & Rebleeding & $\begin{array}{c}\text { Cardiovascular } \\
\text { disease }\end{array}$ & Cancer & Violence & Total \\
\hline Surgical .. &. & 6 & 8 & 1 & 2 & 17 \\
Conservative & $\cdots$ & $16^{*}$ & 3 & 2 & 1 & 22 \\
\hline
\end{tabular}

* Significance of difference from surgical group: $P<0.05$.

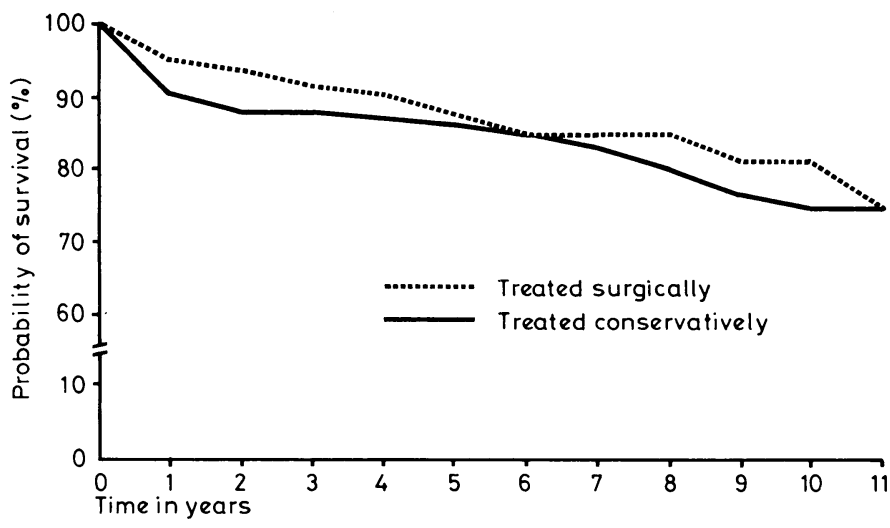

Life-table analysis of 178 patients with single intracranial arterial aneurysm treated surgically or conservatively after mean delay of seven weeks after first bleed (exact figures for each year may be obtained from the authors).

TABLE II-Functional recovery in 139 survivors after mean follow-up period of nine years

\begin{tabular}{lll|c|c|c|c}
\hline & & $\begin{array}{c}\text { Working } \\
\text { full-time }\end{array}$ & $\begin{array}{c}\text { Working } \\
\text { capacity } \\
\text { reduced }\end{array}$ & $\begin{array}{c}\text { Not } \\
\text { working }\end{array}$ & Total \\
\hline $\begin{array}{ccc}\text { No treated surgically .. } \\
\text { No treated conservatively }\end{array}$ & $\ldots$ & $\ldots$ & 36 & 14 & $\begin{array}{c}19^{*} \\
24^{+}\end{array}$ & $\begin{array}{c}69 \\
70\end{array}$ \\
\hline & Total & $\ldots$ & 65 & 31 & 43 & 139 \\
\hline
\end{tabular}

Of these patients, 3 needed assistance and 2 were completely disabled.

* Of these patients, 3 needed assistance and 2 were completely disabled.
$(47 \%)$ had a normal working capacity, $31(22 \%)$ had a reduced working capacity, and $43(31 \%)$ were unable to work (table II). A total of $130(94 \%)$ were fully independent in their daily lives, $5(3.6 \%)$ required assistance, and $4(2.9 \%)$ were completely disabled. There were no significant differences between the two treatment groups in these respects.

\section{Discussion}

Even in the best health services delays may occur in referring patients with subarachnoid haemorrhage for neurosurgical treatment. Our evidence shows that even as late as seven weeks after the initial haemorrhage operation reduces the risk of recurrent bleeding, provided that the patient is in good condition and has only one aneurysm. Our study was carried out during 1964-9, before the operating microscope and spring clips became available. Operating conditions are probably better now, which strengthens the case for operation. Even then, of the 86 patients in our series who were treated surgically, only one died in the postoperative period.

Despite the significant difference in numbers of deaths from rebleeding, we were unable to reduce the total mortality significantly by operation: in the surgical group more people died from cardiovascular disease, which evened out the small difference achieved by surgery. This may be a specifically Finnish problem, as Finns have the highest mortality in the world from cardiovascular disease ${ }^{1011}$ as well as the highest incidence of subarachnoid haemorrhage. ${ }^{1213}$ Figures for cardiovascular disease in white Americans are also high, so that our experience may well be meaningful for this country; but British, Dutch, or Swedish centres, for example, may find our results inapplicable. Certainly surgeons working elsewhere ought to treat figures from one population or centre with caution. Moreover, they should be particularly cautious when non-randomised series are compared. For instance, our survival curve is better than that in Pakarinen's population study ${ }^{1214}$; our patients had already survived for seven weeks and were all in good condition. Selection for possible operation also selects for a favourable outcome without operation. ${ }^{1+15}$

The case for operation is further strengthened, despite the similar overall mortality figures, by one other factor: deaths from cardiovascular disease occurred in patients with an average age of 53 years, while those from rebleeding occurred at an average age of 43 years. Possibly a graded scale should be used, reserving more aggressive treatment for younger patients, and more conservative for the aged.

This study was supported by the Paavo Nurmi Foundation.

Detailed figures for each year of the life-table analysis may be obtained from Dr Markku Kaste.

\section{References}

${ }^{1}$ McKissock, W, Richardson, A, and Walsh, L, Lancet, 1960, 1, 1203.

2 McKissock, W, Richardson, A, and Walsh, L, Lancet, 1962, 2, 417.

${ }^{3}$ McKissock, W, Richardson, A, and Walsh, L, Lancet, 1965, 1, 873.

4 'Troupp, H, and af Björkesten, G, fournal of Neurosurgery, 1971, 35, 20.

${ }^{5}$ Graf, C J, and Nibbelink, D W, Stroke, 1974, 5, 559.

${ }^{6}$ Nibbelink, D W, Torner, J C, and Henderson, W G, Stroke, 1977, 8, 202.

' Winn, H R, Richardson, A E, and Jane, J A, Transactions of the American Neurological Association, 1973, 98, 148.

* Winn, H R, Richardson, A E, and Jane, J A, Annals of Neurology, 1977, 1,358

9 Winn, H R, Richardson, A E, and Jane, J A, fournal of Neurosurgery, 1977, 47, 727 .

10 Keys, A, Circulation, 1970, 41, suppl No 1.

11 World Health Organisation, Myocardial Infarction Community Registers. Copenhagen, WHO Regional Office for Europe, 1976.

12. Pakarinen, S, Acta Neurologica Scandinavica, 1967, 43, suppl No 29.

${ }_{13}$ Aho, K, Incidence, Profile and Early Prognosis of Stroke. Meder-Offset, Espoo, 1975.

${ }^{14}$ Alvord, E C, jun, et al, Archives of Neurology, 1972, 27, 273.

${ }^{15}$ Richardson, A E, Jane, J A, and Payne, P M, Fournal of Neurosurgery, 1964, 21, 266. 